Wilfrid Laurier University

Scholars Commons @ Laurier

$11-2-1998$

\title{
Multi-site Proton Interactions with Natural Organic Matter
}

D. Scott Smith

Wilfrid Laurier University, ssmith@wlu.ca

James R. Kramer

McMaster University

Follow this and additional works at: https://scholars.wlu.ca/chem_faculty

Part of the Chemistry Commons

\section{Recommended Citation}

Smith, DS, Kramer, JR. Multi-site proton interactions with natural organic matter. Environment International 1999;25:307-314.

This Article is brought to you for free and open access by the Chemistry at Scholars Commons @ Laurier. It has been accepted for inclusion in Chemistry Faculty Publications by an authorized administrator of Scholars Commons @ Laurier. For more information, please contact scholarscommons@wlu.ca. 


\title{
MULTI-SITE PROTON INTERACTIONS WITH NATURAL ORGANIC MATTER
}

\author{
D. Scott Smith and James R. Kramer \\ McMaster University, School of Geography and Geology, Hamilton, ON, L8S 4M1, Canada
}

EI 9808-191 M (Received 26 August 1998; accepted 2 November 1998)

\begin{abstract}
Water samples from various locations in Norway were used to isolate natural organic matter (NOM). The NOM was isolated using both reverse osmosis and low-pressure low-temperature evaporation for each sample site. These samples were titrated from $-\log \left[\mathrm{H}^{+}\right] 3$ to 11 at 0.1 unit intervals. The data were analyzed using the Discrete Site Analysis (DISI) technique for $\mathrm{pK}_{\mathrm{a}}$ intervals of 0.2 . The acidity constants are grouped into four classes: strong $\left(\mathrm{pK}_{\mathrm{a}}<5\right)$, intermediate strong $\left(5.1<\mathrm{pK}_{\mathrm{a}}<7.5\right)$, intermediate weak $\left(7.6<\mathrm{pK}_{\mathrm{a}}<9.2\right)$, and weak $\left(\mathrm{pK}_{\mathrm{a}}>9.3\right)$. All samples, regardless of isolation method, were found to contain strong and weak ligands, along with some intermediate ligands. For the same sample site, the concentration of these ligands were found to be dependent on isolation method and titration direction (acid then base vs. base then acid). In addition, the concentration and classes of ligands present were found to vary between sample sites. Suwannee River fulvic acid was analyzed as a reference sample, and was qualitatively similar to the NOM samples but quantitatively different. Overall, the differences in pKa spectra due to isolation method and/or titration direction are almost as significant as differences between sample location, but there are no consistent trends in effects of isolation method or titration direction on characterization of NOM. O1999 Elsevier Science Ltd
\end{abstract}

\section{INTRODUCTION}

Natural organic matter (NOM) contains a number of sites that bind protons and metals. The nature of the molecule will influence both the $\mathrm{pK}_{\mathrm{a}}$ distribution and the specific site concentration. Typically, the $\mathrm{pK}_{\mathrm{a}}$ distribution has been interpreted from acid-base titration curves. Simple one or two site interpretations do not reflect the complex nature of the $\mathrm{pK}_{\mathrm{a}}$ distribution. Various discrete and continuous functions (Borkovec et al. 1996; Černík et al. 1995; de Wit et al. 1993; Buffle et al. 1990) have been proposed for assessment of acid-base properties, as well as Gaussian distributions (Perdue et al. 1984). These methods fit functions of the measured $\mathrm{pH}$ data to a multi-site model for the humic substance, and may or may not include electrostatic effects (de Wit et al. 1993). In most cases, the humic substance is treated as a mixture of monoprotic binding sites, but this mixture may contain discrete sites or be represented by a continuous function.
The data can be treated as adsorption phenomena (Borkovec et al. 1996) using linear superposition of Langmuir isotherms or as thermodynamic binding phenomena (Brassard et al. 1990), using a summation of monoprotic ligands. In either case, the mathematics describing the system are essentially the same. Extracting parameters from the data is an ill-posed problem though (Borkovec et al. 1996), meaning that most classical least-squares solutions become unstable. Regularized least squares (Borkovec et al. 1996; Černik et al. 1995 ) is one method to solve ill-posed problems. Using this, a penalty function is added to make the fitted parameters agree with some assumption about the system. The usual assumptions are for a few discrete sites or for a continuous smooth function. The method of Buffle et al. (1990) involves calculation of a normalized function called the Site Occupation Distribution Function (SODF) which relates buffer intensity to the 
differential free energy of the complexation sites present. This method cannot be used to look at proton binding at discrete sites; it represents the binding properties as a continuous function. This method is conceptually good, but the quality of the data often limits its' usefulness.

Here the Discrete Site (DISI) analysis approach of Brassard et al. (1990) is used. This method was selected because there is ambiguity in continuous affinity distributions for humic substances (Borkovec et al. 1996), and a discrete site approach is more amenable for use in any future modeling efforts. The linear programming method of Brassard et al. (1990) is similar to the regularized least-squares approach used by Borkovec et al. (1996) and has proven robust in previous research efforts (Brassard et al. 1990; Kramer et al. 1991).

\section{EXPERIMENTAL DETAILS}

NOM samples were obtained as part of an international co-operation, the NOM-typing project (Chairman E. Gjessing, Agder College, Norway). Suwannee River fulvic acid was obtained from the International Humic Substances Society (IHSS). NOM-isolates were obtained in powdered form, as both reverse osmosis (RO) and low-pressure low-temperature (EV) isolates. Samples are from various freshwater locations in Norway, selected to span a variety of types of watersheds. Description of sampling sites and sample preparation are given in Gjessing et al. (1998). In this paper, the samples will be designated by isolation method (RO or EV) and by sampling site number, where the numbering scheme for the May (1996) samples is as follows: Trehørningen is NOM-1, Hellerudmyra is NOM-2, Aurevann is NOM-3, Maridalsvann is NOM4, Birkenes is NOM-5, Humex is NOM-6, Gjerstad (limed) is NOM-7, Gjerstad (unlimed) is NOM-8, and for October (1996) Hellerudmyra is referred to as NOM-9. In addition, Suwannee River fulvic acid is referred to as NOM-10.

NOM-isolates were suspended in water to yield a final dissolved organic carbon concentration between 10 and $20 \mathrm{mg}$ of $\mathrm{C} / \mathrm{L}$. Samples were prepared 1 to $2 \mathrm{~h}$ prior to titration. Titrations were performed by an initial addition of $\mathrm{HCl}$ to bring the $\mathrm{pH}$ to around 3, followed by titration with $\mathrm{NaOH}$. In addition, several selected samples were analyzed by titration with $\mathrm{HCl}$ after addition of base. Standard $\mathrm{HCl}$ (Anachemia, NY, USA) was used and $\mathrm{CO}_{2}$ free $\mathrm{NaOH}$ (Anachemia, $\mathrm{NY}$, USA) was standardized against the $\mathrm{HCl}$. The samples were continually blanketed with nitrogen scrubbed using Ascarite to remove $\mathrm{CO}_{2}$. This was done to avoid contamination of the samples with $\mathrm{CO}_{2}$. Titrations were carried out at $20.0 \pm 0.3^{\circ} \mathrm{C}$ and an ionic strength of $0.1 \mathrm{~mol} / \mathrm{L}$, made up by $\mathrm{KNO}_{3}$. The constant ionic strength is required for the integrity of the electrode system as well as to maintain a defined system with respect to the proton reaction. Thus, all fitted parameters are considered conditional values with respect to the experimental conditions and the initial state of the NOM-typing samples.

Titrations were carried out with a Tanager Autotitration system (Tanager, Ancaster, ON, Canada). This system has a stability of $0.05 \mathrm{mV}$, or about $0.001 \mathrm{pH}$ equivalent units. The system is programmed to dispense variable amounts of titrant to obtain equal $\mathrm{mV}$ intervals. A constant interval is obtained by using a continuous estimate of the derivative of the titration curve. In addition, the system is programmed for attainment of steady state equilibrium between each addition of titrant. This is achieved by assessment of a time frame (e.g., $20 \mathrm{~s}$ ) at which the change in slope of data and the variability of data (noise) are statistically assessed against preset precision values. If the slope is not significantly different from zero in the interval, the titration is allowed to proceed. An interval of $5.9 \mathrm{mV}$ $(0.1 \mathrm{pH})$ was used for these titrations in the $\mathrm{pH}$ range 3 to 11 with a precision of $0.005 \mathrm{mV}$. The titration range was limited because outside this range the free ligand term in the charge balance expression (Eq. 6) is insignificant relative to the concentration of other species, and the data cannot be used for meaningful parameter fitting.

The Wilhelm electrode (Sjöberg and Lövgren 1993) was used in conjunction with a Ross glass electrode (model 8103, Orion, MA, USA) to maintain a defined junction potential. The system was calibrated five times against a blank solution at the same ionic strength (I) and temperature conditions as the samples. The calibration followed the design of Sjöberg and Lövgren (1993), where $\mathrm{E}$ is the potential in $\mathrm{mV}$ :

$$
E=a_{0}+a_{1} \log \left[\mathrm{H}^{+}\right]+a_{2} \frac{\left[\mathrm{H}^{+}\right]}{I}+a_{3} \frac{K_{w}}{I \times\left[H^{+}\right]}
$$

The calibration parameters were determined by multiple linear regression of blank titrations. The parameters correspond to the intercept $\left(a_{0}\right)$, the slope 
$\left(a_{1}\right)$, the acidic junction potential $\left(a_{2}\right)$, and the basic junction potential $\left(a_{3}\right)$. If the junction potential parameters were zero, then the calibration would become the traditional Nernst function. $K_{w}$, the dissociation constant for water, was adjusted for temperature effects as in Sjöberg and Lövgren (1993). The stability of the system permitted a one-point calibration $(1 \mathrm{mM} \mathrm{HCl})$ to redetermine $\mathrm{a}_{0}$ before and after each titration.

\section{PARAMETER FITTING}

The DISI analysis proposed by Brassard et al. (1990) was used to fit parameters to the titration data. The parameters included the concentrations of ligands and the acid neutralizing capacity (ANC). In the approach used here, the acidity constants are fixed and the corresponding ligand is assigned a concentration, where zero is a possible value. DISI assumes a summation of independent monoprotic reactions that reflect the reactive ligands. At a hydrogen ion concentration, $\left[\mathrm{H}^{+}\right]$, functional groups, $\mathrm{L}_{\mathrm{i}}^{-}$equilibrate with the protonated sites, $\mathrm{HL}_{\mathrm{i}}$, according to the following reaction:

$$
\mathrm{HL}_{\mathrm{i}}=\mathrm{H}^{+}+\mathrm{L}_{\mathrm{i}}^{-}
$$

and the concentration of a specific site is defined as the sum of the bound and free ligand:

$$
\mathrm{C}_{\mathrm{i}}=\left[\mathrm{HL}_{\mathrm{i}}\right]+\left[\mathrm{L}_{\mathrm{i}}^{-}\right]
$$

For equilibrium at a monoprotic site,

$$
\mathrm{K}_{\mathrm{a}}=\frac{\left[\mathrm{H}^{+}\right]\left[\mathrm{L}_{\mathrm{i}}^{-}\right]}{\left[\mathrm{HL}_{\mathrm{i}}\right]}
$$

and combining Eqs. 3 and 4:

$$
\left[\mathrm{L}_{\mathrm{i}}^{-}\right]=\mathrm{C}_{\mathrm{i}} \frac{\mathrm{K}_{\mathrm{i}}}{\left[\mathrm{H}^{+}\right]+\mathrm{K}_{\mathrm{i}}}
$$

Equation 5 can be incorporated into a charge balance expression for a titration curve for a sample containing n monoprotic acids:

$$
c_{b}+c_{a}+\left[\mathrm{H}^{+}\right]-\left[\mathrm{OH}^{-}\right]=-A N C+\sum_{i=1}^{n} c_{i} \frac{K_{i}}{\left[\mathrm{H}^{+}\right]+K_{i}}
$$

where $c_{a}, c_{b}$, and ANC are the acid and base titrant concentrations added and the initial ANC, respectively. Note that $C_{i}$ and $K_{i}$ are "conditional" values $\left(C^{\prime} K^{\prime}\right)$ because they are dependent on temperature, ionic strength, and competition from other metals.

Equation 6 can be simplified into a linear function:

$$
\begin{gathered}
\text { LIGAND }=-\operatorname{ANC}+\mathrm{C}_{1} \alpha_{1}+\mathrm{C}_{2} \alpha_{2}+\mathrm{C}_{3} \alpha_{3}+\ldots \\
\text { where } \alpha_{i}=\frac{\mathrm{K}_{\mathrm{i}}}{\left[\mathrm{H}^{+}\right]+\mathrm{K}_{\mathrm{i}}}
\end{gathered}
$$

where the term LIGAND is the concentration of negative charge resulting from the deprotonated ligands, and corresponds to the left side of Eq. 6. Thus, the $\mathrm{pK}_{\mathrm{a}}$ "spectrum" is approximated by a series of equal $\log \mathrm{K}_{\mathrm{a}}$ intervals chosen by the investigator. In DISI, these intervals are equal in $\operatorname{logK}_{\mathrm{a}}$ and are normally the same limits as that of the $\mathrm{pH}$ (note, $\alpha$ varies between 0 and 1 , depending on the $\mathrm{pH}-\mathrm{pK}_{\mathrm{a}}$ values).

There is another constraint upon Eq. 7. The solution must be formulated such that $C_{i} \geq 0$. In addition, since the $\mathrm{pK}_{\mathrm{a}} \mathrm{s}$ are discrete, the minimization of error function is written as the absolute of the sum of the error of fit, $\sum\left|e_{i}\right|=$ minimum. This minimization will emphasize differences among $C_{i}$ and for $C_{i}=0$, which is a possible solution. A least-squares minimization would tend to de-emphasize differences between peaks and zero values for $\mathrm{C}_{\mathrm{i}}$. These constraints make linear programming the best method for solving Eq. 7, which imposes nonnegativity constraints and performs a minimization of the absolute error.

All data analysis was performed using in-house Matlab $^{\text {TM }}$ (The MathWorks, MA, USA) programs. For the linear programming problem, the matrices were set up as in Brassard et al. (1990) and the Matlab linear programming routine, which uses an active set strategy, was used (Grace 1992). In defining the linear programming problem, the initial and final $\mathrm{pK}_{\mathrm{a}}$ matched the initial and final $\mathrm{pH}$ for the titration. The $\mathrm{pK}_{\mathrm{a}}$ interval was set at 0.2 . These conditions resulted in the determination of $\mathrm{pK}_{\mathrm{a}}$ 's between 3 and 11 with a resolution of 0.2 .

\section{DISCUSSION}

The calibration parameters for potential (mV) vs. $\left[\mathrm{H}^{+}\right]$were determined using Eq. 1. The best fit parameters were determined as $531 \pm 5$ for $a_{0}, 56.0 \pm 0.8$ for $a_{1}, 83 \pm 2$ for $a_{2}$, and finally $136 \pm 4$ for $a_{3}$. The slope of 


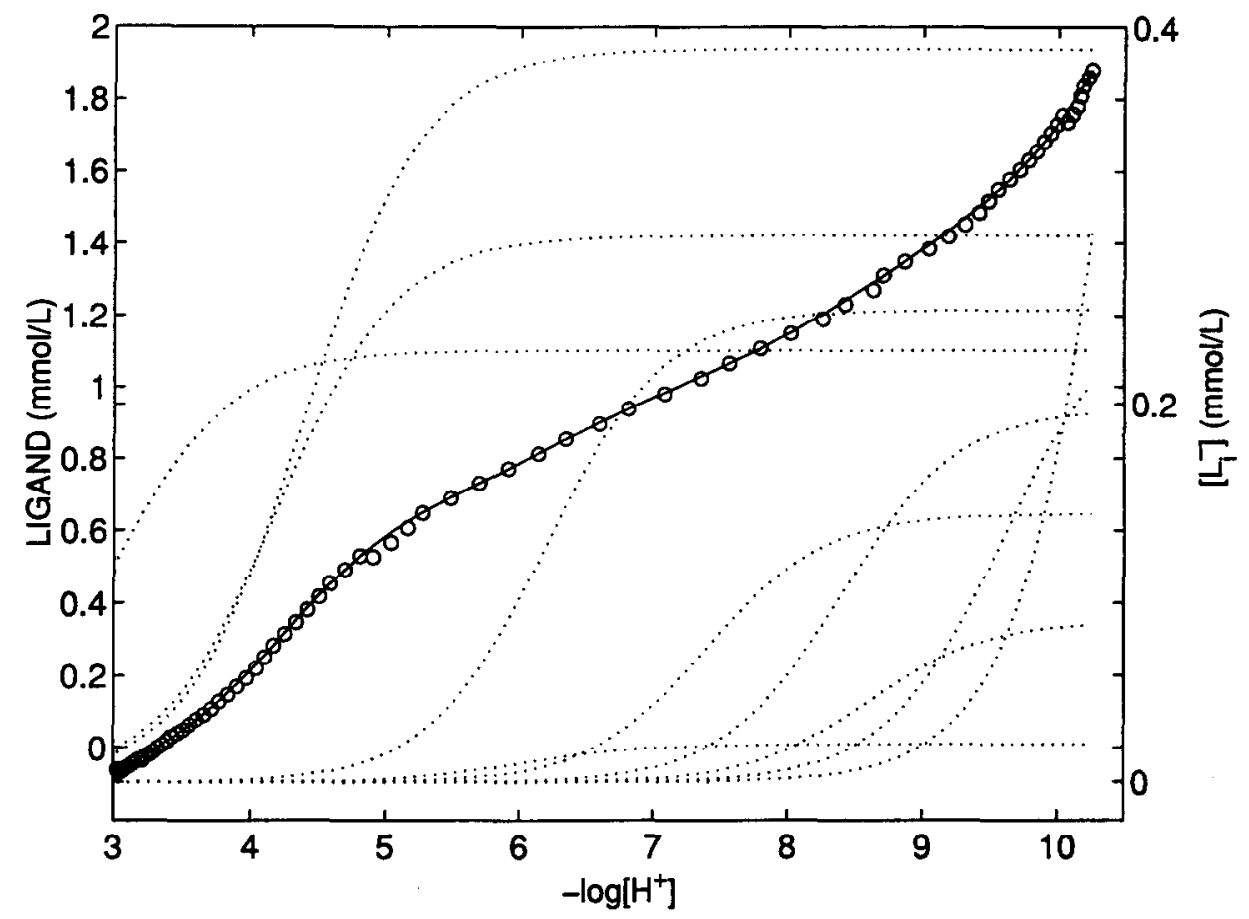

Fig. 1. $-\log \left[\mathrm{H}^{+}\right]$vs. LIGAND (Eq. 7) for NOM-5 (Birkenes) low pressure vacuum evaporative isolate (left axis). The data is represented by open circles and the best fit line by a solid line. The dotted lines correspond to the right axis and represent concentrations of $L_{i}^{-}$for the ligands with non zero concentrations.

56 would have been 59 if the electrode responded exactly Nernstian. The junction potential coefficients of -83 and 136 are higher than the coefficients of -49.7 and 21.4 determined by Sjöberg and Lövgren (1993) for the Wilhelm electrode. The replication error of 1 to $2 \%$ for all the coefficients is acceptable, however.

An example of the linear programming fitting of LIGAND as defined in Eq. 7 is given in Fig. 1. The calculated curve (solid line) closely matches the observed data (open circles). Superimposed on this figure (dotted lines) are the calculated concentrations for each of the free ligands $\left(\mathrm{L}_{\mathrm{i}}^{-}\right)$. There are 10 ligands necessary to describe the observed data. Three of the ligands are fully deprotonated above $\mathrm{pH} 5$, one above $\mathrm{pH} 7$, two above $\mathrm{pH} \mathrm{9,} \mathrm{and} \mathrm{the} \mathrm{remaining} \mathrm{four} \mathrm{ligands} \mathrm{are} \mathrm{not}$ fully deprotonated within the $\mathrm{pH}$ range of the experiment.

The $\mathrm{pK}_{\mathrm{a}}$ spectra for the nine NOM-isolates are shown in Fig. 2, along with the spectra determined for Suwannee River fulvic acid for comparison. The solid bars represent RO-isolates and the open bars represent the EV-isolates, except for Suwannee River fulvic acid that was only isolated in one way. The results for Suwannee River fulvic acid agree with literature values for total carboxylic content. For example, Leenheer et al. (1995) reported carboxylic site densities between
4.15 and $6.8 \mu \mathrm{mol} / \mathrm{mg}$ of Suwannee River fulvic acid. If the ligands determined here are summed up to $\mathrm{pH} 7$, which is the usual titration endpoint for total carboxylic determination, then the carboxylic content for Suwannee River fulvic acid is $6.0 \mu \mathrm{mol} / \mathrm{mg}$ of fulvic acid. This value corresponds exactly with the best value selected by Leenheer et al. (1995).

All samples show peaks corresponding to relatively strong acids around $\mathrm{pK}_{\mathrm{a}}$ of 4 and weak acids with $\mathrm{pK}_{\mathrm{a}} \mathrm{s}$ around 10 . In addition, most samples show peaks in the intermediate $\mathrm{pK}_{\mathrm{a}}$ range. Qualitatively the $\mathrm{pK}_{\mathrm{a}}$ results for the two isolation methods agree fairly well; the same classes of acidic sites are observed in both isolates. A more thorough comparison is possible if ligands are grouped into four classes: strong acidic ligands $\left(\mathrm{pK}_{\mathrm{a}}<5\right)$, intermediate strong ligands $(5.1<$ $\left.\mathrm{pK}_{\mathrm{a}}<7.5\right)$, intermediate weak $\left(7.6<\mathrm{pK}_{\mathrm{a}}<9.2\right)$, and weak $\left(\mathrm{pK}_{\mathrm{a}}>9.3\right)$. The results of summing the ligand concentrations over this grouping are given in Table 1.

Further, the samples can be compared by plotting the concentrations for the various groupings. Figure 3 shows the concentrations of EV- vs. RO-isolates. The line on each plot corresponds to where all the points would lie if there was no difference in the two isolation methods. For the RO-isolates, the strongly acidic sites and the weakly acidic sites have values close to 

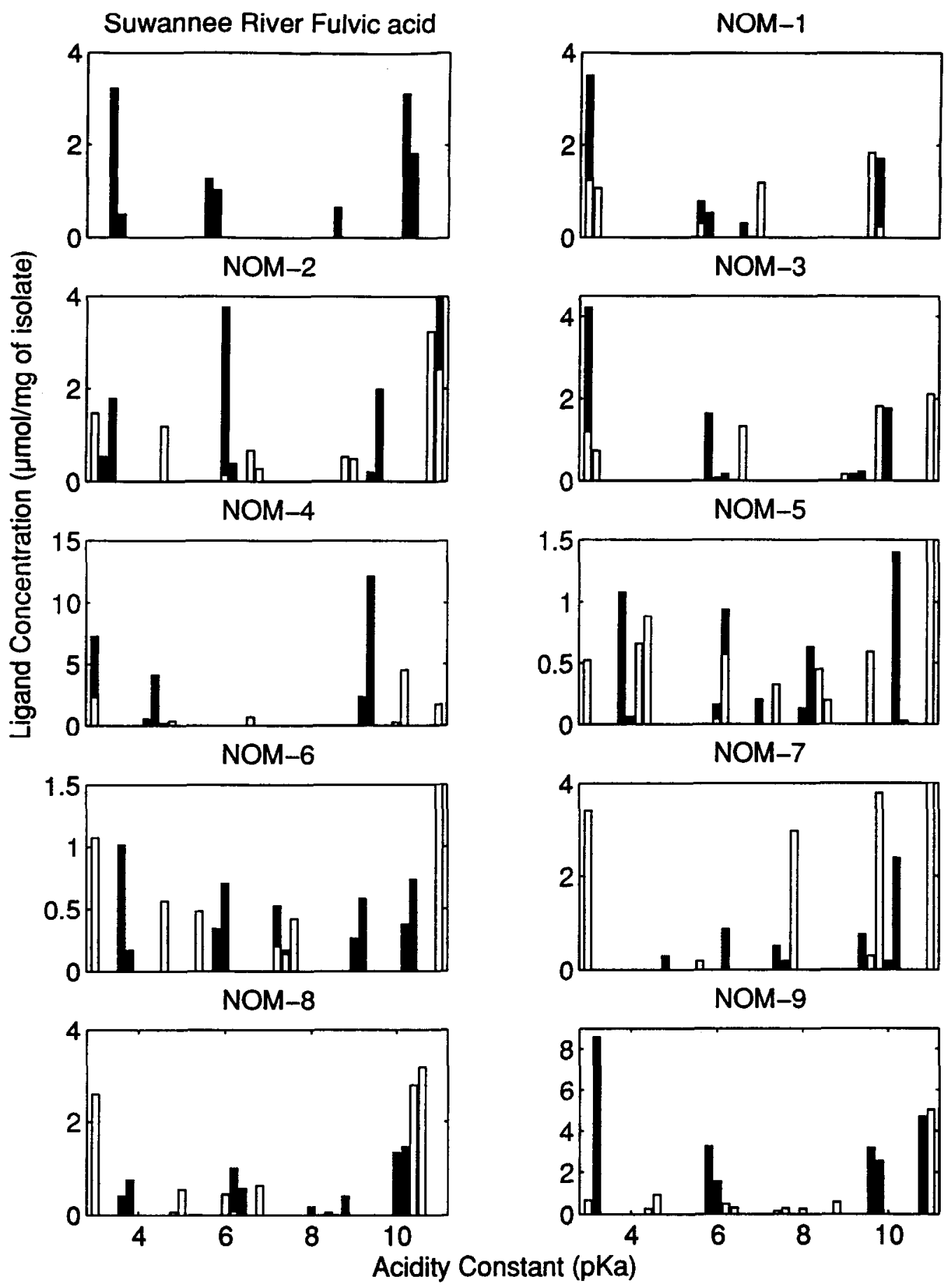

Fig. 2. $\mathrm{pK}_{\mathrm{a}}$ spectra for NOM-isolates and Suwannee River fulvic acid. RO-isolates are indicated by solid bars and EV-isolates by open bars.

Suwannee River fulvic acid; except NOM-9 and NOM4 , which are dramatically $(\sim 320 \%)$ more concentrated in both classes.

In general, the values for the RO- and EV-isolates do not quantitatively agree. This indicates that one or both of the methods alters the samples. Overall, the EV sam- ples show less variation and lower concentrations then the RO samples. Only NOM-1 is similar in all four classes, and NOM- 2, 5, 6, and 7 are similar in three out of four ligand classes. Details of the relations between different total ligand concentrations are described below for the four ligand classes. 
Table 1. Total ligand concentrations for four functional group classes. The values for base then acid titrations are presented as RO/EV. The sample numbers correspond to the numbering scheme given in the experimental section. For NOM-1, 3, 4, and 5, the RO sample results for base then acid titration direction are shown in brackets.

\begin{tabular}{lccccc}
\hline & \multicolumn{5}{c}{ Ligand concentrations for indicated $\mathrm{pK}_{\mathrm{a}}$ class $(\mu \mathrm{mol} / \mathrm{mg}$ of isolate $)$} \\
\cline { 2 - 6 } Sample & $<5$ & $5.1-7.5$ & $7.6-9.2$ & $>9.3$ & Total \\
\hline 1 & $3.5(3.0) / 2.3$ & $1.6(2.5) / 1.5$ & $0(0) / 0$ & $4.9(10.7) / 2.1$ & $10.0(16.2) / 5.9$ \\
2 & $2.3 / 2.7$ & $4.2 / 1.1$ & $0 / 1.0$ & $4.3 / 5.7$ & $10.8 / 10.5$ \\
3 & $4.2(1.6) / 1.9$ & $1.9(0.042) / 1.3$ & $0(2) / 0.15$ & $2.0(3.5) / 3.9$ & $8.5(7.5) / 7.3$ \\
4 & $11.9(3.4) / 2.9$ & $0(5.6) / 0.71$ & $0(0) / 0$ & $12.1(8.1) / 6.5$ & $24(17.1) / 10.1$ \\
5 & $1.1(1.1) / 2.1$ & $1.3(0) / 0.94$ & $0.76(0) / 0.65$ & $1.4(4.6) / 5$ & $4.6(5.7) / 8.7$ \\
6 & $1.2 / 1.6$ & $1.7 / 0.82$ & $0.26 / 0.41$ & $1.1 / 4.6$ & $4.3 / 7.4$ \\
7 & $2.5 / 3.4$ & $1.4 / 0.19$ & $0.19 / 3.0$ & $3.3 / 5.3$ & $7.4 / 11.9$ \\
8 & $1.2 / 3.2$ & $1.6 / 1.1$ & $1.7 / 0.05$ & $2.8 / 5.9$ & $7.3 / 10.3$ \\
9 & $8.6 / 1.8$ & $4.8 / 0.9$ & $0 / 1.1$ & $13.7 / 5$ & $27.1 / 9.9$ \\
10 & 3.7 & 2.3 & 0.64 & 4.9 & 11.5 \\
\hline
\end{tabular}
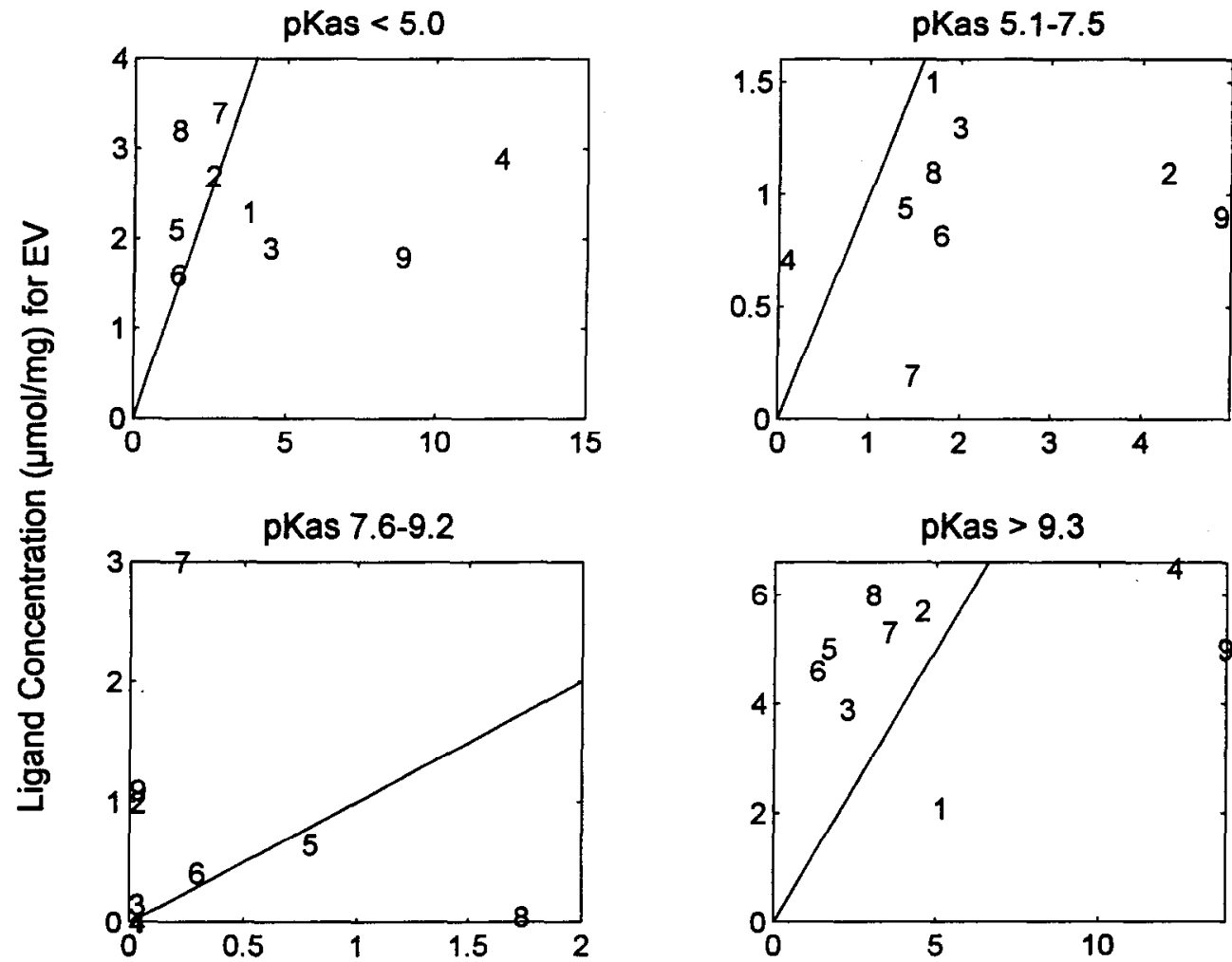

Ligand Concentration ( $\mu \mathrm{mol} / \mathrm{mg})$ for RO

Fig. 3. Comparison plots for total ligand concentrations over various pKa ranges for the two isolation methods. The sloped line corresponds to a line where the RO- and EV-isolates are equivalent. The numbers correspond to the sample numbers, as given in the experimental section.

For the strongly acidic ligands, NOM-2, 5, 6, and 7 are similar in RO- and EV-isolates, but NOM-8 is higher in the EV-isolate and NOM-1, 3, 9, and 4 are higher in RO-isolates. For the intermediate strong ligands, only NOM-1 is similar for both isolation methods, NOM-4 is higher in EV and the rest of the samples are more concentrated in the RO-isolates. The intermediate weak class of ligands has NOM-1, 3, 4, 5, and 6 yielding similar results for both isolation methods but NOM-2, 3, and 7 are overestimated in the EV- 
isolates and NOM-8 is overestimated in the ROisolates. Finally, for the weakly acidic components of NOM-2, 3, and 7, the results are similar in RO and EV samples, NOM-5, 6, and 8 and NOM-1 are slightly overestimated by the EV- and RO-isolation methods, respectively, NOM-4 and 9 are higher in the RO-isolates.

For the seasonal sample (Hellerudmyra), the RO sample in October (NOM-2) is five times greater then the May sample (NOM-9) in both the strong and weak classes of ligands. The intermediate ligands have values closer to each other for the May and October samples. This can be interpreted as productivity during the summer, increasing the proton reactive sites at the Hellerudmyra sampling site. Comparison of the EVisolates shows little change in the October and May samples regardless of class, though. The sites along the Trehørningen catchment (NOM-1, 2, and 3) show no obvious trend with location.

Perdue (1985) summarized the $\mathrm{pK}_{\mathrm{a}}$ values for model organic ligands that might be incorporated in NOM. The acidic groups vary from sample to sample, but they consist mainly of carboxyl $(\mathrm{COOH})$ with $\mathrm{pK}_{\mathrm{a}}$ values from 3 to 5 , and phenolic $(\mathrm{OH})$ with $\mathrm{pK}_{\mathrm{a}} \mathrm{s}$ from about 9 to 11 . The intermediate $\mathrm{pK}_{\mathrm{a}}$ values between 5 and 9 could be attributed to a wide variety of functional groups, including $\beta$-dicarbonyl compounds, enols, and alcohols, as well as surface sites on inorganic substrates.

Inorganic proton binding ligands are possible given the relatively high levels of iron and aluminum in the samples and the $40-60 \%$ ash content (Gjessing et al. 1998). In an effort to assess the contribution from inorganic surface sites, an X-Ray Diffraction (XRD) pattern was obtained for NOM-4-RO and compared to standard spectra. It was found that sodium chloride, calcite, and sodium sulphate were components of the sample. These salts would be expected to dissolve in the sample and the carbonate should not yield a $\mathrm{pK}_{\mathrm{a}}$ because $\mathrm{CO}_{2}$ was scrubbed from the samples. It is possible that inorganic ligands were not observed in the XRD pattern because $\mathrm{Al} / \mathrm{Fe}-\mathrm{O}-\mathrm{OH}$ 's were $\mathrm{XRD}$ amorphous or at non-detectable levels.

Some of the proton binding sites may be due to $\mathrm{Al} / \mathrm{Fe}-\mathrm{O}-\mathrm{OH}$ 's. For example, $\gamma$-aluminum hydroxide has two intrinsic $\mathrm{pK}_{\mathrm{a}}$ 's, one at 7.2 and another at 9.5; amorphous silica has a $\mathrm{pK}_{\mathrm{a}}$ value of 6.8 and amorphous iron hydroxide has two $\mathrm{pK}_{\mathrm{a}} \mathrm{s}$, one at 6.6 and another at 9.1 (Schindler and Stumm 1987). Kramer et al. (1991) reported $\mathrm{pK}_{\mathrm{a}} \mathrm{s}$ of $2.8,4.8,6.6$, and 8.7 for kaolinite.
$\mathrm{Al} / \mathrm{Fe} / \mathrm{Si}-\mathrm{O}-\mathrm{OH}$ 's typically have specific site densities of about 10 times less than NOM, but the smaller concentration, intermediate $\mathrm{pK}_{\mathrm{a}} \mathrm{s}$ could be due to proton binding with these inorganic ligands.

The results also depend on the sequence of titration, acid then base vs. base then acid. The four RO samples titrated by both methods have different site densities in the four ligand classes. These results are summarized in Table 1. NOM-1 agrees well for strong acidic sites, but weak sites are $100 \%$ higher in the base first titration. Sample 5 shows agreement for the strong sites and again higher concentration for the weak sites. Samples 3 and 4 have lower values for the strong sites using base then acid but fair agreement for the weaker sites. Overall, the differences in results depending on titration direction are as significant as the differences depending on isolation method. Differences can be attributed to the irreversibility of the NOM-H system. In particular, coagulation resulting from acidification of the samples to $\mathrm{pH} 3$ in the acid then base titration scheme, changes the nature of the sample, and the change is not reversed by increasing the $\mathrm{pH}$. This could lead to decreases in ligand concentration because sites are no longer available for binding of protons.

\section{CONCLUSIONS}

DISI of acid-base titration data of Suwannee River fulvic acid recovers the literature value for total carboxylic content $(6.0 \mu \mathrm{mol} / \mathrm{mg}$ of fulvic acid, Leenheer et al. 1995). The method yields qualitatively similar results for both RO- and EV-isolates in that, apparent carboxylic $(\sim 4)$ and phenolic ligands $(\sim 10)$ are resolved. Quantitatively, the isolation methods differ; only NOM-1 yields similar results for both methods. Overall, the EV-isolate has lower concentrations and less variation between samples. In addition, the results are dependent on the order of addition of titrant; results for the base then acid titration sequence differ from acid then base titration sequence. The differences between titration directions are as significant as the difference between isolation methods and these effects are almost as significant as differences between sampling sites. For a full understanding of the nature of NOM-proton binding at these sampling sites, titrations of unfractionated water would be necessary to assess the effects of NOM concentration methods. In addition, the data from two titrations should be combined, both starting from ambient $\mathrm{pH}$, with one going up in $\mathrm{pH}$ and the other going down. 
Acknowledgment-The authors would like to acknowledge the members of the NOM-Typing project organization committee. In addition, DSS would like to acknowledge an Ontario Graduate Scholarship for financial support and JRK would like to acknowledge funding from the Natural Sciences and Engineering Research Council of Canada.

\section{REFERENCES}

Borkovec, M.; Rusch, U.; Černík, M.; Koper, G.J.M.; Westall, J.C. Affinity distributions and acid-base properties of homogeneous and heterogeneous sorbents: Exact results versus experimental data inversion. Colloids Surfaces 107: 285-296; 1996.

Brassard, P.; Kramer, J.R.; Collins, P.V. Binding site analysis using linear programming. Environ. Sci. Technol. 23: 195-201; 1990.

Buffle, J.; Altmann, R.S.; Filella, M.; Tessier, A. Complexation by natural heterogeneous compounds: Site occupation distribution functions, a normalized description of metal complexation. Geochim. Cosmochim. Acta 54: 1535-1553; 1990.

Črnik, M.; Borkovec, M.; Westall, J.C. Regularized least squares method for the calculation of discrete and continuous affinity distributions for heterogenous sorbents. Environ. Sci. Technol. 29: 413-425; 1995.

de Wit, J.C.M.; Riemsdijk, W.H.; Koopal, L.K. Proton binding to humic substances. 2. Chemical heterogeneity and adsorption models. Environ. Sci. Technol. 27: 2015-2022; 1993.
Gjessing, E.T.; Egeberg, P.K.; Hikedal, J.T. Natural organic matter in drinking water. The "NOM-typing project", background and basic characterization of the original water samples and NOM isolates. Environ. Int. 25: 145-159; 1998.

Grace, A. Optimization toolbox user's guide. Natick, MA: The MathWorks, Inc.; 1992.

Kramer, J.R.; Collins, P.; Brassard, P. Characterization of multiple functional groups on kaolinite. Mar. Chem. 36: 1-8; 1991.

Leenheer, J.A.; Wershaw, R.L.; Reddy, M.M. Strong-acid, carboxyl-group structures in fulvic acid from the Suwannee River, Georgia. 1. Minor structures. Environ. Sci. Technol. 29: 393-398; 1995.

Perdue, E.M.; Reuter, J.H.; Parrish, R.S. A statistical model of proton binding by humus. Geochim. Cosmochim. Acta 48: 1257$1263 ; 1984$.

Perdue, M.E. Acidic functional groups of humic substances. In: Aiken, R.G.; McKnight, D.M.; Wershaw, R.L.; MacCarthy, P., eds. Humic substances in soil, sediment and water. New York, NY: John Wiley and Sons; 1985: 493-526.

Schindler, P.W.; Stumm, W. The surface chemistry of oxides, hydroxides and oxide minerals. In: Stumm, W., ed. Aquatic surface chemistry. New York, NY: Wiley-Interscience; 1987: 83-107.

Sjoberg, S.; Lơvgren, L. The application of potentiometric techniques to study complexation reactions at the mineral/water interface. Aquat. Sci. 55: 324-335; 1993. 